\title{
Gene Expression Analysis of Induced Plum Pox Virus Resistance in Peach (Prunus Persica) by Almond (P. Dulcis) Grafting
}

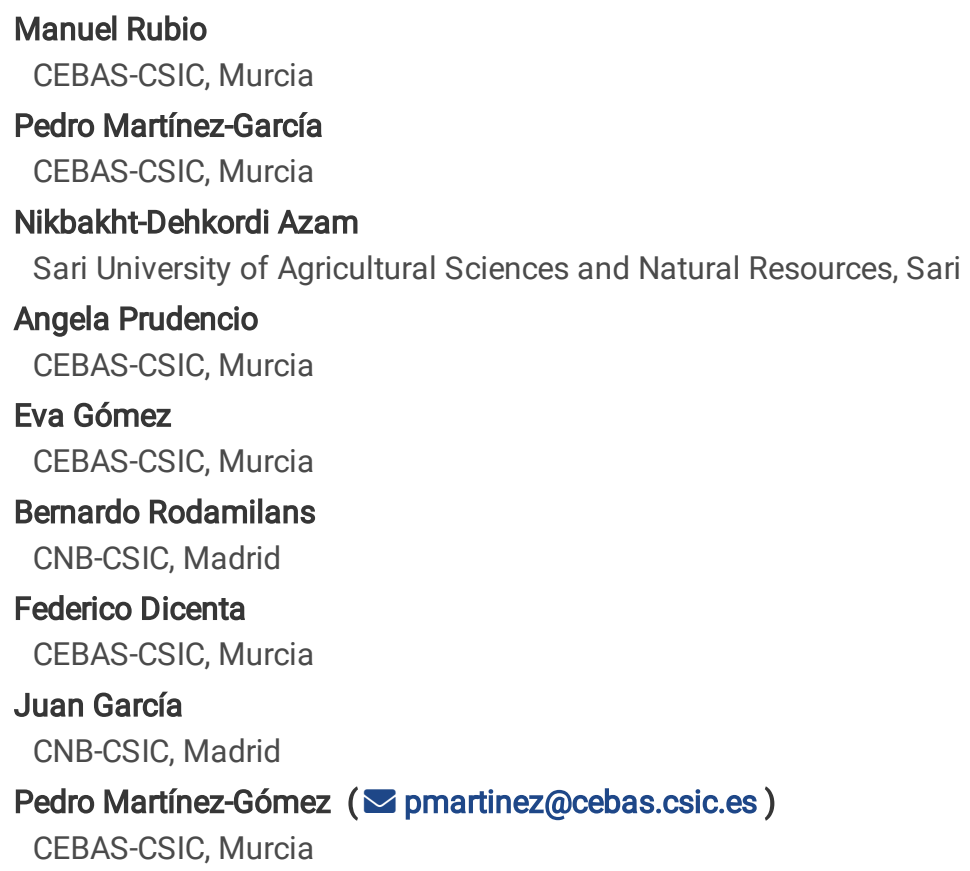

\section{Research Article}

Keywords: PPV, sharka disease, peach, almond, breeding, plant-virus interaction, RNA-Seq, RTqPCR

Posted Date: January 18th, 2021

DOI: https://doi.org/10.21203/rs.3.rs-145720/v1

License: (c) (i) This work is licensed under a Creative Commons Attribution 4.0 International License. Read Full License 


\section{Abstract}

No natural sources of resistance to Plum pox virus (PPV, sharka disease) have been identified in peach. However, previous studies have demonstrated that grafting 'Garrigues' almond onto 'GF305' peach seedlings heavily infected with PPV can progressively reduce disease symptoms and virus accumulation. Furthermore, grafting 'Garrigues' onto 'GF305' has completely prevented virus infection. This study aims to analyse the rewiring of gene expression associated with this resistance to PPV transmitted by grafting through phloem using RNASeq and RTqPCR analysis. A total of 18 candidate genes were differentially expressed after grafting 'Garrigues' almond onto healthy 'GF305' peach. Among the up-regulated genes, a HEN1 homolog stands out, which, together with the differential expression of RDR-and DCL2-homologs in some of the conditions assayed, suggests that the RNA silencing machinery is activated by PPV infection and can contribute to the resistance induced by 'Garrigues' almond. Glucan endo-1,3-Beta D-Glucosidase could be also relevant for the 'Garrigues'induced response, since its expression is much higher in 'Garrigues' than in 'GF305'. We also discuss the potential relevance of the following in PPV infection and 'Garrigues'-induced resistance: several pathogenesis-related proteins, No apical meristem proteins, the transcription initiation factor TFIIB, the Speckle-type POZ protein and a number of proteins involved in phytohormone signalling.

\section{Introduction}

Stone (Prunus) fruit trees are affected by a large number of viral diseases that can cause important economic losses ${ }^{1}$. Sharka, caused by Plum pox virus (PPV), is however the most significant of these diseases due to the reduced fruit quality and premature fruit drop it causes ${ }^{2}$. The rapid natural spread of PPV by aphid vectors contributes to the high epidemiological impact of the disease. This agent has been classified as a quarantine pathogen and as one of the Top 10 Viruses in crops ${ }^{3,4}$. Although there is no antiviral treatment that can be applied to infected trees or orchards, sharka may be managed by varied approaches, such as quarantine and management activities, certification programs, vector control and the use of resistant varieties. The best current method for controlling PPV is preventing the spread of the virus to new fruit-growing areas ${ }^{5}$, although genetic resistance is the definitive control strategy for PPV in affected areas ${ }^{1,6,7}$. However, in the case of peach [P. persica (L.) Batsch], the most important Prunus species with an annual production of 24.66 million tons in 2017 (http://www.fao.org/faostat/en/\#data), no natural sources of resistance have been identified ${ }^{8,9}$. The lack of resistance to PPV in peach could be solved by incorporating resistant genes from other related species. P. ferganensis (Kostov and Rjabov) and P. davidiana (Carrière) Franch were the first species described as potential sources of resistance to PPV in peach. Nevertheless, the transmission of resistance has been questioned, and the importance of the genetic background in the effectiveness of this strategy has been highlighted ${ }^{10}$. Another alternative for introducing PPV resistance in peach is the use of the closely related almond [P. dulcis (Miller) Webb] species. With an important degree of resistance to different PPV isolates, almond is a good candidate as a resistance donor via interspecific crosses ${ }^{11}$.

Previous studies have demonstrated that grafting the almond cultivar 'Garrigues' onto 'GF305' peach (a very susceptible PPV indicator) seedlings heavily infected with PPV can progressively reduce disease symptoms and virus accumulation ${ }^{7}$. This response appears to be specific between almond and peach. Furthermore, grafting 'Garrigues' onto 'GF305' before PPV inoculation completely prevented virus infection, showing that resistance is constitutive and not induced by the virus ${ }^{12}$. In a recent study, differences in gene expression were studied after PPV infection in 'GF305' peach leaves using high-throughput Illumina RNA sequencing (RNA-Seq). The observed results showed that early PPV infection in peach leaves, without disease symptoms, is associated with an induction of genes coding for factors involved in pathogen resistance such as jasmonate biosynthesis elements, chitinases and Lys-M proteins. On the other hand, when the virus was installed, the overexpression of Dicer-like (DCL) protein 2a genes could demonstrate the induction of defensive responses related to RNA silencing counteracted by the HCPro silencing suppressor of the virus ${ }^{13}$.

A recent comparison of hormonal balances in healthy and PPV-D-inoculated 'GF305' peach trees, either grafted or not grafted with the almond cultivar 'Garrigues', showed important differences between treatments ${ }^{14}$. PPV inoculation produced a significant increase in gibberellin GA3 and abscisic acid (ABA) and a decrease in the other phytohormones analysed, including the cytokinin trans-zeatine (tZ), gibberellin GA4, ethylene precursor 1-aminocyclopropane-1-carboxylic acid (ACC), salicylic acid (SA) and jasmonic acid (JA). These imbalances are related to the virus infection and the presence of chlorosis symptoms, particularly in the case of the ABA concentration. Additionally, grafting 'Garrigues' onto 'GF305' produced an increase in GA3, GA4, SA and ABA and a decrease in the rest of the phytohormones analysed (tZ, ACC and JA). However, grafting 'Garrigues' almond onto PPV-inoculated 'GF305' peach produced the opposite effect in some phytohormones, resulting in an increase in tZ, SA and JA. The results of this work suggest a main role for SA in almondinduced resistance in peach, with additional contributions from $\mathrm{tZ}$ and $\mathrm{JA}$.

It is well known that virus induces different defence responses related to RNA silencing in different plant species ${ }^{15,16}$. However, the PPV resistance induced by 'Garrigues' induced systemic resistance (ISR) grafting in peach does not require an initial viral infection, suggesting that this response is not linked with the induction of antiviral RNA silencing, nor related to responses such as induced systemic resistance

Page $2 / 20$ 
(ISR) or systemic acquired resistance (SAR) ${ }^{17}$. It therefore seems more likely that some specific factor of 'Garrigues' almond spreads through the graft to 'GF305' and contributes to blockage of the multiplication or movement of the virus. In this context, mobility of various macromolecules including DNA, RNA and proteins has been well documented between the scion and stock, suggesting that the graft could be a means for the horizontal genetic transfer ${ }^{18,19}$. Not only phenotypic traits but also the core molecular building blocks could be altered in the grafted individuals ${ }^{20,21}$. In addition, endogenous small RNAs of all size classes (21-24 nt) can move across the graft union ${ }^{22}$. This movement can give rise to specific physiological reprogramming and epigenetic changes in the different tissues ${ }^{23,24}$.

Our work aims to analyse the regulation of gene expression of the resistance to PPV transmitted to peach 'GF305' by grafting with 'Garrigues' almond cultivars, focusing on the differential expression patterns shown and comparing the different treatments studied.

\section{Results}

PPV resistance evaluation. The results shown in Table 1 confirm the high susceptibility of 'GF305'peach to PPV (all inoculated plants showed clear symptoms and were ELISA-DASI and RT-PCR positive in sample B) and the resistance of the almond variety 'Garrigues' to the assayed PPV isolate [no plants showed disease symptoms (Fig. 1) or were ELISA-DASI or RT-PCR positive (samples F and G)]. In the first two phenotyping cycles, four infected 'GF305' plants grafted with 'Garrigues' (D) were positive by ELISA and RT-PCR, and only one of them showed noticeable symptoms during the second cycle. In addition, we performed a third phenotyping cycle, during which one of the infected 'GF305' plants grafted with 'Garrigues' still showed the presence of PPV but was symptomless. The effect of 'Garrigues' grafting was also very clear when 'GF305' plants already grafted with 'Garrigues' were inoculated (sample E). In this case, we never observed symptoms on the 'GF305' rootstock, and only one plant gave positive RT-PCR results (exclusively in evaluation cycle 2). 
Table 1

Evaluation of behaviour against PPV in the assayed plant material. The samples assayed included control healthy 'GF305' peach rootstocks (A); PPV-infected 'GF305' rootstocks showing very severe sharka symptoms (B); 'GF305' peach rootstocks grafted with healthy 'Garrigues' (C); PPV-infected 'GF305' rootstocks showing sharka symptoms grafted with healthy 'Garrigues' (D); and healthy 'GF305' peach rootstock grafted with healthy 'Garrigues' which were later inoculated with PPV at the end of the first cycle of evaluation (E). In addition,

'Garrigues' almond samples grafted onto healthy (F) and inoculated 'GF305' (G) rootstocks were included in the study. In bold type the evaluated plant material GF305 = peach and Garrigues = almond.

\begin{tabular}{|c|c|c|c|c|c|c|c|c|c|c|c|c|}
\hline \multirow[b]{2}{*}{$\begin{array}{l}\text { Plant } \\
\text { model }\end{array}$} & \multirow[b]{2}{*}{ Sample } & \multicolumn{3}{|c|}{ Cycle 1} & \multicolumn{4}{|c|}{ Cycle 2} & \multicolumn{4}{|c|}{ Cycle 3} \\
\hline & & $\mathrm{N}^{1}$ & Symptoms ${ }^{2}$ & $\begin{array}{l}\text { ELISA- } \\
\text { DASI }^{3}\end{array}$ & $\mathrm{~N}^{1}$ & Symptoms ${ }^{2}$ & $\begin{array}{l}\text { ELISA- } \\
\text { DASI }^{3}\end{array}$ & $\begin{array}{l}\text { RT- } \\
\text { PCR }^{4}\end{array}$ & $\mathrm{~N}^{1}$ & Symptoms ${ }^{2}$ & $\begin{array}{l}\text { ELISA- } \\
\text { DASI }^{3}\end{array}$ & $\begin{array}{l}\text { RT- } \\
\text { PCR }^{4}\end{array}$ \\
\hline $\begin{array}{l}\text { GF305 } \\
\text { Control }\end{array}$ & A & 8 & $0(0.0)$ & $\begin{array}{l}0 \\
(0.052)\end{array}$ & 8 & $0(0.0)$ & $\begin{array}{l}0 \\
(0.058)\end{array}$ & 0 & 7 & $0(0.0)$ & $\begin{array}{l}0 \\
(0.064)\end{array}$ & 0 \\
\hline $\begin{array}{l}\text { GF305 + } \\
\text { PPV }\end{array}$ & B & 8 & $8(3.3)$ & $\begin{array}{l}8 \\
(3.529)\end{array}$ & 8 & $8(4.2)$ & $\begin{array}{l}8 \\
(3.209)\end{array}$ & 8 & 7 & $7(3.1)$ & $\begin{array}{l}7 \\
(1.435)\end{array}$ & 7 \\
\hline $\begin{array}{l}\text { GF305 } \\
\text { Control + } \\
\text { Garrigues }\end{array}$ & C & 8 & $0(0.0)$ & $\begin{array}{l}0 \\
(0.059)\end{array}$ & 7 & $0(0.0)$ & $\begin{array}{l}0 \\
(0.056)\end{array}$ & 0 & 6 & $0(0.0)$ & $\begin{array}{l}0 \\
(0.061)\end{array}$ & 0 \\
\hline $\begin{array}{l}\text { GF305+ } \\
\text { PPV + } \\
\text { Garrigues }\end{array}$ & D & 8 & $2(1.0)$ & $\begin{array}{l}1 \\
(1.222)\end{array}$ & 6 & $1(1.0)$ & $\begin{array}{l}4 \\
(1.519)\end{array}$ & 4 & 5 & $0(0.0)$ & $\begin{array}{l}1 \\
(0.286)\end{array}$ & 1 \\
\hline $\begin{array}{l}\text { GF305 } \\
\text { Control + } \\
\text { Garrigues } \\
+ \text { PPV }\end{array}$ & E & 8 & $0(0.0)$ & $\begin{array}{l}0 \\
(0.059)\end{array}$ & 8 & $0(0.0)$ & $\begin{array}{l}0 \\
(0.060)\end{array}$ & 1 & 7 & $0(0.0)$ & $\begin{array}{l}0 \\
(0.056)\end{array}$ & 0 \\
\hline $\begin{array}{l}\text { GF305 } \\
\text { Control + } \\
\text { Garrigues }\end{array}$ & $\mathrm{F}$ & 8 & $0(0.0)$ & $\begin{array}{l}0 \\
(0.061)\end{array}$ & 6 & $0(0.0)$ & $\begin{array}{l}0 \\
(0.057)\end{array}$ & 0 & 6 & $0(0.0)$ & $\begin{array}{l}0 \\
(0.056)\end{array}$ & 0 \\
\hline $\begin{array}{l}\text { GF305+ } \\
\text { PPV + } \\
\text { Garrigues }\end{array}$ & G & 8 & $0(0.0)$ & $\begin{array}{l}0 \\
(0.052)\end{array}$ & 7 & $0(0.0)$ & $\begin{array}{l}0 \\
(0.052)\end{array}$ & 0 & 5 & $0(0.0)$ & $\begin{array}{l}0 \\
(0.057)\end{array}$ & 0 \\
\hline \multicolumn{13}{|c|}{${ }^{1}$ Number of biological replications evaluated. } \\
\hline \multicolumn{13}{|c|}{$\begin{array}{l}2 \text { Number of repetitions with sharka symptoms, between parenthesis the mean values of the repetitions with symptoms in a scale from } \\
0 \text { to } 5 \text {. }\end{array}$} \\
\hline \multicolumn{13}{|c|}{${ }^{3}$ Number of repetitions ELISA-DASI positive, between parenthesis the mean OD values of the assayed replications. } \\
\hline umbe & tio & & itive. & & & & & & & & & \\
\hline
\end{tabular}

RNA-Seq transcriptome profiles. A total of 1,024 million paired end reads of 125 bp were generated from the seven samples tested

(Table 2). After eliminating adapter sequences, empty reads and low-quality sequences, 1,021 million high-quality reads ( $99 \%)$, which were named clean reads, were obtained. By iterative alignment, $75.8 \%$ of the clean reads mapped in the reference genome Peach v2.0 (www.rosaeae.org), while $24.2 \%$ of clean reads were not recognised by any of the eight pseudo region-chromosomes. Alignment values in the peach genome ranged from averages of $78.7 \%$ in peach samples to $68.2 \%$ in almond. On the other hand, 2.15 million unmapped reads ( $0.21 \%$ of the total clean reads) were mapped in the PPV genome (Table 2). We can assume that 15,152 and 44 supposed PPV reads from control plants (samples A, C and F, respectively) are contaminations. Ultimately, we were able to observe the clear effect of grafting 'Garrigues' almond onto 'GF305' peach. Comparing sample B with sample D, we noticed a 25-fold decrease in PPV-mapped reads during the second phenotyping cycle. And in the case in which 'GF305' was grafted with 'Garrigues' and then inoculated with PPV (sample E), the number of reads was almost 1,000 times lower than in infected non-grafted 'GF305' (B) (Table 2). These data fit well with symptom observation and virus detection data obtained from ELISA and RT-PCR during the second cycle of evaluation in which samples were collected (Table 1). 'Garrigues' sample G showed 45 PPV-mapped reads. Although we cannot rule out the possibility that these few reads were derived from virus that remained in the infected 'GF305' rootstock after the alleviation due to almond grafting, they are probably contaminations like those found in samples $\mathrm{A}, \mathrm{C}$ and $\mathrm{F}$.

Host transcriptional changes. Table 3 summarises differences in gene expression between the different samples analysed. The total number of expressed peach genes that were tested in the different comparisons ranged from 18,832 in the D/C comparison to 20,643 in comparison D/B. A total of 18,808 expressed genes were tested in the comparison of almond samples (G/F). In addition, 5,815 differently expressed genes (DEGs) were identified in the different comparisons analysed using the cuffmerge and cuffdiff tool (Table 3 ). Considering 
the effect of PPV inoculation/infection, 1,102 and 548 DEGs were detected on 'GF305' after inoculation (comparison B/A, Table S2) and inoculation plus almond grafting (comparison D/C, table S5), respectively. Moreover, 439 DEGs were detected on 'Garrigues' almond when PPV-inoculated and non-inoculated plants were compared (comparison G/F; Table S8). In assessing the effect of grafting 'Garrigues' almond onto healthy 'GF305', 823 DEGs were detected (comparison C/A; Table S3). Focusing on both effects in 'GF305' (PPV infection + 'Garrigues' grafting), we studied two comparisons, D/B (Table S4) and E/B (Table S6), which showed 1,163 and 1,113 DEGs, respectively. The last comparison performed was to study the effect of shifting the order of inoculation and 'Garrigues' grafting (comparison E/D, Table S7) with 627 DEGs. After filtering the data by log fold change $>1$ and $<-1$ ) and q-val $<0.05$, the number of DEGs decreased drastically to 197 genes (147 unique) (Table 3). No differentially expressed genes were detected between 'Garrigues' grafted onto infected or healthy rootstocks (G/F). Regarding the effect of PPV infection/inoculation on 'GF305', 44 genes were detected in non-grafted plants (B/A), while in comparisons between grafted and non-grafted plants D/B and E/B, 31 and 47 filtered DEGs were detected, respectively, with 14 shared genes. Comparing the infected 'GF305' grafted with 'Garrigues' (D) with the same treatment but shifting the order of inoculation and grafting (E/D) and with control 'GF305' grafted with 'Garrigues' (D/C), we observed a similar number of filtered DEGs (28 and 29 , respectively), with 8 shared genes in this case (Table 3). The effect of almond grafting on healthy 'GF305' rootstocks (comparison C/A) showed the lowest number of filtered DEGs (18), with an equilibrium between up- and down-regulation (10/8). We observed that the heavy infection of sample B (infected 'GF305' control) generally triggered the largest deregulation of genes.

Functional analysis of differentially expressed genes. The 5,815 differentially expressed genes (DEGs) across samples represented a total of 3,269 different genes. From this set, 3,210 were assigned with a UNIPROTKB ID, and 1,115 were assigned with one or more GO terms using PANTHER (Supplementary Table S10; Fig. 2). The most represented functional category was "Cellular component" with 2,782 hits, followed by "Biological process" and "Molecular function", with 1,721 and 1,058 hits, respectively. The most represented cellular component terms were cell (G0:0005623) and cell part (G0:0044464), with 713 hits each, followed by the "Biological process" term cellular process (G0:0009987), with 558 hits. Another highly represented "Cellular component" term was organelle (G0:0043226) (438 hits). The term with the second highest percentage of hits (453 hits) in "Biological process" was metabolic process (G0:0008152). Regarding "Molecular function" terms, the most represented term was catalytic activity (546 hits). The 197 filtered DEGs (Table 3) corresponded to 147 different genes. Only one gene could not be mapped by PANTHER (Prupe_2G011500), and 56 were associated with at least one GO term (Supplementary Table S11; Fig. 2). The distribution pattern of GO terms in this restricted list was similar to that of the complete set of DEGs (Fig. 3). Again, the functional category with the highest number of hits was "Cellular component" with 130 hits, followed by "Biological process" and "Molecular function" with 83 and 54 hits, respectively. As in the total set of DEGs, the most represented terms were two "Cellular component" terms, cell (G0:0005623) and cell part (G0:0044464), with 38 hits each. The most represented "Biological process" terms were cellular process (G0:0009987) and metabolic process (G0:0008152), with 27 and 25 hits, respectively. For "Molecular function", the most represented term was catalytic activity (G0:0003824) (30 hits).

Table 2

Mapping characteristics of samples assayed including the two biological replicates by treatment: control healthy 'GF305' peach seedlings (A); PPV-infected 'GF305' seedlings showing very severe sharka symptoms (B); 'GF305' peach seedlings grafted with healthy 'Garrigues' (clonal) (C); PPV-infected 'GF305' seedlings showing sharka symptoms grafted with healthy 'Garrigues' (clonal) (D); and healthy 'GF305' peach seedlings grafted with healthy 'Garrigues' (clonal) which were later inoculated with PPV at the end of the first cycle of evaluation (E). In addition, 'Garrigues' almond samples grafted onto healthy (F) and inoculated 'GF305' $(\mathrm{G})$ rootstocks were included in the study. In bold type: the evaluated plant material, GF305 = peach and Garrigues = almond. $A^{\prime}=$ single forward and $A^{\prime \prime}=$ single reverse

\begin{tabular}{|c|c|c|c|c|c|}
\hline Treatments & Sample & Total reads & Clean reads & $\begin{array}{l}\text { Reads mapped } \\
\text { P. persica v } 2.0\end{array}$ & $\begin{array}{l}\text { Reads mapped } \\
\text { PPV genome }\end{array}$ \\
\hline GF305 Control & $A\left(A^{\prime}+A^{\prime \prime}\right)$ & $151,699,038$ & $151,376,821$ & $123,331,659(81.5 \%)$ & $15(0.00001 \%)$ \\
\hline GF305 + PPV & $\mathrm{B}\left(\mathrm{B}^{\prime}+\mathrm{B}^{\prime \prime}\right)$ & $159,272,116$ & $158,812,159$ & $125,187,942(78.8 \%)$ & $2,071,915(1.30 \%)$ \\
\hline GF305 Control + Garrigues & $C\left(C^{\prime}+C^{\prime \prime}\right)$ & $142,956,238$ & $142,296,978$ & $113,078,192(79.5 \%)$ & $152(0.0001 \%)$ \\
\hline GF305 + PPV + Garrigues & $D\left(D^{\prime}+D^{\prime \prime}\right)$ & $143,511,454$ & $143,041,550$ & $109,499,620(76.6 \%)$ & $80,703(0.06 \%)$ \\
\hline GF305 Control + Garrigues + PPV & $E\left(E^{\prime}+E^{\prime \prime}\right)$ & $148,551,466$ & $148,233,453$ & $114,097,915(77.0 \%)$ & $1,904(0.0013 \%)$ \\
\hline GF305 Control + Garrigues & $F\left(F^{\prime}+F^{\prime \prime}\right)$ & $140,514,568$ & $140,158,744$ & $88,206,273(62.9 \%)$ & $44(0.00003 \%)$ \\
\hline GF305 + PPV + Garrigues & $G\left(G^{\prime}+G^{\prime \prime}\right)$ & $138,038,412$ & $137,569,619$ & $101,163,774(73.5 \%)$ & $45(0.00003 \%)$ \\
\hline Total & & $1,024,543,292$ & $1,021,489,324$ & $774,565,345(75.8 \%)$ & $2,154,778(0.21 \%)$ \\
\hline
\end{tabular}


Table 3

Total (p-val< 0.05$)$ and filtered (q-val < 0.05) differentially expressed genes (DEGs) including the number of up- and down-regulated DEGs in peach and almond genes in the seven comparisons performed comparing control (A) and infected GF305 peach showing strong sharka symptoms (B); control GF305 (C) grafted with Garrigues almond (F) and infected GF305 grafted (D) with Garrigues (G); and control GF305 grafted with Garrigues almond and later inoculated with PPV (E). In bold type: the evaluated plant material, GF305 $=$ peach and Garrigues $=$ almond.

\begin{tabular}{|c|c|c|c|c|c|c|c|}
\hline Comparison of transcriptomes & $\begin{array}{l}\text { Sample } \\
\text { comparison }\end{array}$ & $\begin{array}{l}\text { Total } \\
\text { identified } \\
\text { genes }\end{array}$ & $\begin{array}{l}\text { Total } \\
\text { tested } \\
\text { genes }\end{array}$ & $\begin{array}{l}\text { Total DEG } \\
\text { genes }\end{array}$ & $\begin{array}{l}\text { Filtered } \\
\text { DEG genes }\end{array}$ & $\begin{array}{l}\text { DEG } \\
\text { Up }\end{array}$ & $\begin{array}{l}\text { DEG } \\
\text { Down }\end{array}$ \\
\hline \multicolumn{8}{|l|}{ Effect of PPV inoculation/infection } \\
\hline GF305 + PPV vs. GF305 Control & B vs. A & 27,121 & 19,335 & 1,102 & 44 & 9 & 35 \\
\hline $\begin{array}{l}\text { GF305 + PPV + Garrigues vs. GF305 } \\
\text { Control + Garrigues }\end{array}$ & D vs. C & 27,036 & 18,832 & 548 & 29 & 20 & 9 \\
\hline $\begin{array}{l}\text { GF305 + PPV + Garrigues vs. GF305 } \\
\text { Control + Garrigues }\end{array}$ & G vs. F & 27,203 & 18,808 & 439 & 0 & - & - \\
\hline \multicolumn{8}{|l|}{ Effect of almond grafting } \\
\hline $\begin{array}{l}\text { GF305 Control vs. GF305 Control + } \\
\text { Garrigues }\end{array}$ & C vs. A & 27,011 & 19,906 & 823 & 18 & 10 & 8 \\
\hline \multicolumn{8}{|l|}{$\begin{array}{l}\text { Effect of PPV infection and almond } \\
\text { Grafting }\end{array}$} \\
\hline $\begin{array}{l}\text { GF305 + PPV + Garrigues vs. GF305 + } \\
\text { PPV }\end{array}$ & D vs. B & 27,143 & 20,643 & 1,163 & 31 & 23 & 8 \\
\hline $\begin{array}{l}\text { GF305 Control + Garrigues + PPV vs. } \\
\text { GF305 + PPV }\end{array}$ & $\mathrm{E} v s . \mathrm{B}$ & 27,131 & 19,362 & 1,113 & 47 & 30 & 17 \\
\hline \multicolumn{8}{|l|}{$\begin{array}{l}\text { Effect of shifting the order of inoculation } \\
\text { and grafting }\end{array}$} \\
\hline $\begin{array}{l}\text { GF305 Control + Garrigues + PPV vs. } \\
\text { GF305 + PPV + Garrigues }\end{array}$ & E vs. D & 26,589 & 18,865 & 627 & 28 & 6 & 22 \\
\hline Total & & & & 5,815 & 197 & 98 & 99 \\
\hline
\end{tabular}

The overrepresentation analysis was carried out with PANTHER to compare our complete DEG list with the reference peach genome (Supplementary Table S10). In the case of "Biological process", the results showed the highest over-representation for several G0 terms, such as posttranscriptional gene silencing (G0:0016441), posttranscriptional gene silencing by RNA (G0:0035194) and gene silencing by RNA (GO:0031047) (5.19-fold enrichment). Other terms with remarkable over-representation were beta-glucan biosynthetic process (G0:0051274), mitotic cytokinesis (G0:0000281) and cytoskeleton-dependent cytokinesis (G0:0061640). Most of the GO terms of the DEGs in our experiment with statistically significant different representation compared to the peach genome were under-represented. Under representation was maximum for the terms tRNA metabolic process (G0:0006399) and peptidyl-amino acid modification (G0:0018193) (impoverishment values of 5.58- and 4.17-fold, respectively. Regarding "Cellular component", the only terms significantly over-represented were cytosolic large ribosomal subunit (G0:0022625), cytosolic ribosome (G0:0022626) and cytosolic part (G0:0044445), with fold enrichments of 2.09, 1.96, and 1.73, respectively. Again, the number of under-represented terms in our DEG list is larger than that of overrepresented terms, and membrane protein complex (G0:0098796) was the term showing the highest under-representation (three fold). Only five "Molecular function" terms showed a significantly different representation in our DEG list compared to the peach genome (four enriched terms and one impoverished). In this case, calcium ion binding (G0:0005509) was the most prominent term, with a 3.14-fold enrichment value. No statistically significant results were obtained in the overrepresentation analysis with PANTHER of the filtered DEG set for "Molecular function" and "Cellular component" terms (Supplementary Table S11). No significantly under-represented "Biological process" terms were found, either. However, 11 "Biological process" terms showed a significant over-representation in the filtered DEG set. The three brother terms, posttranscriptional gene silencing (G0:0016441), posttranscriptional gene silencing by RNA (G0:0035194) and gene silencing by RNA (GO:0031047), with a 56.64-fold enrichment value, were already identified in the total DEG set. Interestingly, the rest of the over-represented GO terms in the restricted DEG set were also related to the silencing and regulation of gene expression.

Next, the GO analysis was refined by grouping together the filtered DEGs associated with common biological effects. Comparisons associated with the almond grafting effect (CA vs. DB vs. EB, Table 3) yielded a total of 82 filtered DEGs, none of which was shared by the three comparisons (Fig. 3A and Supplementary Table S12). The comparisons of conditions joining almond grafting and PPV infection (DB vs EB, Table 3) shared a total of 14 filtered DEGs (Fig. 3A and Supplementary Table S12). In this set of 82 filtered DEGs, only one could not 
be mapped by PANTHER, and the number of genes annotated with at least one GO term was 19 . The functional category with the highest number of hits was "Cellular component" with 36 hits, followed by "Biological process" and "Molecular function" with 27 and 18 hits, respectively. The most represented term was the "Molecular function" term catalytic activity (GO:0003824) (12 hits), followed by two Cellular component" terms, cell (GO:0005623) and cell part (GO:0044464) (11 hits each), and by two "Biological process" terms, metabolic process (GO:0008152) and cellular process (GO:0009987) (9 hits each) (Supplementary Table S12 and Fig. 3). No statistically significant over- or under-represented terms were found in the overrepresentation analysis for this set of filtered DEGs (Supplementary Table S12).

The four comparisons associated with PPV inoculation/infection (BA vs. DB vs. EB vs. DC, Table 3) resulted in 113 filtered DEGs, and none were shared by the four comparisons (Fig. 3A and Supplementary Table S13). Comparisons of heavily infected non-grafted 'GF305' versus 'GF305' with low or no virus load, either non-grafted (BA) or grafted (DB and EB), shared 10 filtered DEGs (Fig. 3A and Supplementary TS13). In addition, one filtered DEG was shared between comparisons of almond-grafted and non-grafted PPV-inoculated trees (EB) and PPV-inoculated and non-inoculated almond-grafted 'GF305' (DC). In this set of 113 DEGs related to PPV infection, 42 DEGs were annotated with at least one GO-SLIM term, with 225 hits (Supplementary Table S13). Again, the functional category with the highest number of hits was "Cellular component" with 111 hits, followed by "Biological process" and "Molecular function" with 69 and 45 hits, respectively. Among the "Cellular component" terms, cell (G0:0005623) and cell part (G0:0044464) showed the highest number of hits (31), followed by catalytic activity (G0:0003824) (23 hits) in the "Molecular function" category, and cellular process (G0:0009987) (22 hits) and metabolic process (GO:0008152) (22 hits) in the "Biological Process" domain. Thirteen GO terms assigned by PANTHER corresponding to the "Biological process" category were significantly overrepresented in this subset of filtered DEGs in comparison with the $P$. persica reference list (Supplementary Table S13). Nine of them were also overrepresented in the complete list of filtered DEGs, including the three most enriched terms (posttranscriptional gene silencing, G0:0016441; posttranscriptional gene silencing by RNA, G0:0035194; and gene silencing by RNA, G0:0031047) (Supplementary Tables S11 and S13). The enrichment analysis did not obtain significant results for the "Molecular function" or "Cellular component" categories (Supplementary Table S13).

Validation of gene expression profiles using RTqPCR. Fourteen genes were selected based on different criteria for validating RNA-Seq data by RTqPCR analyses in an additional experiment. Some of these genes were selected for their link with the signalling of phytohormones, including a hormone related to gibberellin (GA) growth (Prupe.5G193400; Gibberellin-regulated protein 4) and phytohormones related to stress, like abscisic acid (ABA) (Prupe.1G453700; Dehydration-responsive protein RD22); ethylene (Prupe.7G194400; Ethylene-responsive transcription factor ERF017 and Prupe.4G176200; Ethylene responsive element binding protein (ERBP)-like factor); salicylic acid (SA) (Prupe.1G393400; Chrorismate mutase and Prupe.5G164200; Cytochrome P450 71A1 (CYP71A1).

Most of selected candidate genes, however, code for factors related to the pathogen response, like a Pathogenesis-related thaumatin-like protein (Prupe.8G163300), Glutathione S-Transferase(Prupe.1G039900), a Pathogenesis-related 1 protein (Prupe.1G091400), a No apical meristem protein (Prupe.2G204700), Transcription initiation factor TFIIB (Prupe.3G255800), Glucan endo-1,3-beta-D-glucosidase (Prupe.7G051200) and the Endoribonuclease DICER homolog 2 (DCL2) (Prupe.7G048000). The differential expression of the gene encoding the Speckle-type POZ protein (Prupe.1G488200) is of special interest, since this protein has a meprin and TRAF homology (MATH) domain, and proteins with this domain have been found to be involved in resistance to PPV (Pagny 2012; Zuriaga 2018). The expression trends of eight of the selected genes were similar to those shown by RNA-Seq analysis (Figs. 4 and 5). Pearson correlation coefficients between fragments per kilobase pair of transcript per million mapped reads (FPKM) values from RNA-Seq and relative gene expression (RGE) values from RTqPCR were higher than 0.70 for 12 of the 14 assayed genes. Transcription initiation factor-TFIIB and No apical meristem protein (NAM) are exceptions, with correlation coefficients of 0.61 and 0.70 respectively. The anomalous values of Speckle-type POZ protein in sample $D$ are another example of low correlation between the two analyses. The expression of most analysed genes was higher in leaves showing disease symptoms (sample B) than in non-symptomatic leaves. In addition, grafting 'Garrigues' induced an increase in the expression of the following genes: EREBP-like factor, Chorismate mutase, no-apical meristem protein, Transcription initiation factor-TFIIB, Glucan endo-1.3-beta-D-glucosidase and DCL2 (Figs. 4 and 5).

\section{Discussion}

The "protection effect" of 'Garrigues' was clear in 'GF305' that was inoculated when 'Garrigues' was already grafted (sample E). In this case, no symptoms were ever observed on 'GF305'. From the agronomical point of view, this is the most important effect, since we can graft 'Garrigues' as an intermediate wood on commercial rootstocks (interstock), and later, when the scions have developed, graft the peach varieties. These results open the possibility of using 'Garrigues' as a rootstock or interstock to control PPV in peach, similar to the proposed solution in grapevine ${ }^{25}$ or tomato ${ }^{26}$. The intermediate rootstock model is widely used in agriculture to solve compatibility problems between cultivars or species or to induce specific behaviours such as dwarfing, reduce juvenility, etc. ${ }^{27}$. 
The PPV-resistance response induced by grafting 'Garrigues' onto 'GF305' is associated with a strong transcriptomic imbalance with many changes at the mRNA level as previously described for grafting in other plant species ${ }^{20,25,26}$. The total number of filtered DEGs detected in our seven comparisons combining grafting and infection effects was relatively low (197) compared to previous studies after PPV-infection on peach, with 1,554 DEGs in three comparisons ${ }^{13}$, or apricot, with 437 DEGs in only two comparisons ${ }^{28}$. This low number is probably related to improvements in the phenotyping and sampling method, i.e., selecting all leaves with a similar age, development stage and phytosanitary status in order to reduce effects not linked to PPV or grafting. It is conceivable that a signal from 'Garrigues' moves through the graft to 'GF305' and elicits the resetting program that confers protection against PPV. If we assume that this induction of "resistance" is independent of PPV presence, we must focus on the C/A comparison (Supplementary Table S3). Only 18 DEGs were detected in this comparison. Among these genes, 10 genes were up-regulated after grafting healthy 'GF305' with 'Garrigues' almond (sample C). Notably, the level of expression of these 10 genes was also higher in 'GF305' plants that were inoculated with PPV after grafting with 'Garrigues' and were not infected (sample E) than in healthy non-grafted 'GF305' (sample A) (Supplementary Tables S3 and S6). These up-regulated genes can therefore be considered as potential candidates for involvement in the defensive response induced by 'Garrigues'.

One of the DEGs of the C/A comparison that attracts the most attention is Prupe.4G091400, which is identified as the peach homolog of HUA ENHANCER 1 (HEN1). This DEG encodes an RNA methyltransferase that plays an important role in RNA silencing by methylating SiRNAs ${ }^{29}$. This gene was associated with the brother GO-SLIM terms posttranscriptional gene silencing (GO:0016441), posttranscriptional gene silencing by RNA (GO:0035194) and gene silencing by RNA (GO:0031047). HEN1 was highly enriched in our complete list of DEGs and filtered DEGs (Tables S10 and S11) as well as in the list of filtered DEGs related with PPV infection (Table S13). These GO terms were also associated with the genes Prupe.1G132200, Prupe.4G078900, Prupe.1G332600 and Prupe.1G334500, which code for putative RNAdependent RNA polymerases (RDR) (Table S11). Although differences were not shown to be statistically significant in the C/A comparison, these four genes were expressed at higher levels in non-infected 'GF305' grafted with 'Garrigues' (sample C) than in the healthy non-grafted 'GF305' control (sample A) (Table S3). An RNA silencing-related gene that has been reported to be activated by PPV infection in woody plants is $D C L 2^{13,28}$. Confirming the relationship of $D C L 2$ with PPV infection, this gene (Prupe.7G048000) was significantly overexpressed in 'GF305' trees that recovered from PPV infection by 'Garrigues' grafting (sample D) compared to grafted 'GF305' trees that never suffered PPV infection (samples C and E) (Table S9). This differential expression was confirmed by RT-qPCR analysis (Fig. 5). As in the case of the aforementioned $R D R$ genes, the expression of Prupe.7G048000 was higher in non-infected 'GF305' grafted with 'Garrigues' (sample C) than in uninfected 'GF305' (sample A), although in this case, differences did not reach the threshold of statistical significance (Table S3 and Fig. 5).

A recent translatome profiling study identified one HEN1 homolog, three DCL2 homologs, six RDR1 homologs, and other predicted RNA silencing-related genes up-regulated in both phloem and non-phloem tissues of plum leaves developing PPV infection after a period of coldinduced dormancy ${ }^{30}$. Activation in phloem tissue is especially interesting because it could provide a mobile defensive barrier crossing the grafting junction. These data agree with the results of our study and suggest that antiviral defences related to RNA silencing contribute to the virus resistance established in 'GF305' after grafting with 'Garrigues' almond. Another interesting gene showing statistically significant differential expression in the C/A comparison is Prupe.7G051200, which was identified as a Glucan endo - 1,3-Beta D-G/ucosidase coding for a B-1,3-glucanase of the thaumatin family of Pathogenesis-Related (PR) proteins. It has been reported that virus infection can induce a distinct $B-1,3-$ glucanase activity in mutant plants deficient in this enzymatic activity ${ }^{31}$. Moreover, a thaumatin-like protein accumulated in the apoplast of infected peach after PPV infection ${ }^{32}$. In agreement with these facts, the RNA-seq analysis showed an increase (not statically significant) in the expression of Prupe.7G051200 as well as of Prupe.8G163300 and Prupe.1G091400, encoding another PRrelated thaumatin-like protein and a PR 1-like protein, respectively, associated with PPV infection in non-grafted 'GF305' plants (B/A comparison, Table S9). This was confirmed by RTqPCR (Fig. 5). More importantly, 'Garrigues' almond (samples G and F) showed a much higher level of expression of Prupe.7G051200 than 'GF305' peach (sample A), as revealed by RNA-seq (Tables S2 and S8) and RT-qPCR (Fig. 5), and grafting of 'Garrigues' almond caused a significant increase in the Prupe.7G051200 activity of 'GF305' peach (Table S9 and Fig. 5). The relevance of this increase in the 'Garrigues'-induced resistance is unclear, since deficiency in ß-1,3-glucanase activity has been shown to decrease, rather than enhance, susceptibility to viral disease ${ }^{31}$. Both grafting and infection effects may contribute to the differences in the expression of the 14 DEGs shared in the comparisons DB and EB (Table S12). However, the absence of significant expression differences between samples $C$ and $A$ in all these genes, and the fact that the infection of non-grafted 'GF305' plants caused significant changes in the expression (mainly up-regulation) of most of them (Table S13), suggests that the effect of infection exceeds that of grafting in these DB and EB comparisons.

An important contribution of phytohormonal signalling in PPV infection and resistance has been revealed through a metabolomic analysis conducted by Nikbakht-Dehkordi et al. ${ }^{14}$. Agreeing with this observation, at least four genes differentially expressed in the BA, BD and BE comparisons were involved in phytohormone signalling. These genes, Prupe.1G393400, Prupe.4G176200, Prupe.5G164200 and

Page $8 / 20$ 
Prupe.1G453700, were identified as Chorismate mutase, EREBP-like factor, CYP71A1, and Dehydration-responsive RD22 (Table S9), and their high expression levels in infected non-grafted 'GF305' (sample B) were confirmed by RT-qPCR (Fig. 4). SA is well known to be involved in plant defence, and this hormone has been shown to be involved in the decrease in symptoms induced by grafting 'Garrigues' onto PPVinfected 'GF305' peach ${ }^{14}$. In this regard, chorismate mutase is a key enzyme in the biosynthetic pathway of SA ${ }^{33}$, and the Cytochrome P450 CYP71A1, which encodes the tryptamine 5-hydroxylase that catalyses the conversion of tryptamine to serotonin, is involved in the cross-talk between salicylic acid and serotonin biosynthetic pathways controlling plant defence responses ${ }^{34}$. There are numerous reports showing the relevance of $A B A$ in plant virus infection. In particular, ABA has recently been shown to play a negative role in the response to PPV infection ${ }^{35}$. Dehydration-responsive $R D 22$ is a classical marker of an activated ABA response ${ }^{36}$, and its overexpression in the $B$ sample (Table S9 and Fig. 4) is consistent with the important role played by ABA in PPV infection. The main role of the phytohormone ethylene in plant resistance is in the defence response to necrotrophic pathogens, but there are also reports showing its involvement in viral infections ${ }^{37}$. The involvement of ethylene in PPV is soundly supported by the strong induction of an EREBP-like factorgene associated with a symptomatic PPV infection (sample B, Table S9, Fig. 4). This assumption was reinforced by the much higher expression level of the DEG Prupe.7G194400, identified as Ethylene-responsive transcription factor ERF017, in infected 'GF305' than in the healthy control (247.05 vs 0.559 , Tables S2). Although it could not be considered statistically significant, this difference in expression level was confirmed by an RTqPCR assay (Fig. 4).

To explore the possible involvement of other phytohormones in 'GF305' infection and its recovery by grafting with 'Garrigues', we analysed by RT-qPCR a phytohormone-related gene that did not appear to be differentially expressed in the RNA-seq experiment. Prupe.5G193400, identified as Giberellin-regulated protein 4, showed consistent data in the RNA-seq and RT-qPCR analyses, revealing a notable overaccumulation in the PPV-infected non-grafted RT-qPCR analyses. This result suggests that gibberellins also play a role in the PPV infection of peach trees, and, together with the results discussed above, reflects the complex pattern of phytohormone rearrangements associated with the PPV infection of 'GF305' peach and the resistance induced by 'Garrigues' almond, previously discussed by Nikbakht-Dehkordi et al. ${ }^{14}$. Prupe.2G204700 and Prupe.3G255800 were identified as No apical meristem protein (NAM) and Transcription initiation factor (TFIIB), respectively. NAM proteins are included within the NAC family, a family including members involved in interactions with pathogens ${ }^{38}$. They are transcription factors that can act as negative regulators of resistance to pathogens by suppressing defence-related gene expression. Some NAC proteins can enhance or inhibit the multiplication of viruses by interacting directly with virus-encoded proteins ${ }^{39,40}$. TFIIB is a general transcription factor that forms part of the pre-initiation complex of RNA polymerase II. The structure of TFIIB presents two domains, an imperfect repeat of approximately 70 aa and a TFIl zinc-binding domain. Proteins with this last domain have been shown to be involved in the regulation of responses to biotic and abiotic stresses and in resistance to pathogens ${ }^{41}$. Both RNA-seq and RT-qPCR data revealed induction of Prupe.2G204700 and Prupe.3G255800 by PPV infection (compare B and A samples in Fig. 5). Of note, expression of these two genes was almost not reduced when PPV infection was mitigated by 'Garrigues' grafting, and was enhanced when 'Garrigues' was grafted onto healthy 'GF305' trees (compare samples D vs B and C vs A in Fig. 5). These results suggest that NAM and TFIIB could be relevant not only for PPV infection but also for its healing by 'Garrigues' grafting.

Prupe.1G488200 was identified as a Speckle-type POZ protein, a gene encoding an E3 ubiquitin ligase holding a meprin and TRAF homology (MATH) domain ${ }^{42}$. In Arabidopsis thaliana the MATH-TRAF gene RTM3 encodes a factor involved in the restriction of systemic spread of different potyviruses, including PPV ${ }^{43}$, and at least one other PPV resistance gene has been mapped to a region encompassing seven MATH-TRAF genes ${ }^{44}$. More importantly, PPV resistance in apricot cultivars is extensively linked to the repression of $P a r P M C 1$ and ParPMC2 genes, both encoding MATH family proteins, which are located in the major resistance locus $P P V$ res ${ }^{45,46}$. The downregulation of these genes has been suggested to be caused by an RNA silencing mechanism triggered by the pseudogenisation of the resistance allele of ParPMC2 46,47 . In our study, none of MATH-TRAF genes of the peach syntenic region of the apricot PPVres locus was differentially expressed. However, the expression of Prupe.1G488200, which is also located in chromosome 1, but downstream of the PPVres-related region, was induced by PPV infection (sample B), showing lower expression levels in healthy and grafting-induced recovered peaches (Fig. 5). Whether the role of Speckle-type POZ protein in peach infection is related to that of ParPMC1 and ParPMC2 in apricot and RTM3like proteins in Arabidopsis remains unknown. This study identifies candidate genes involved in peach infection by PPV and its recovery induced by 'Garrigues' almond grafting. However, a larger number of biological replicas is required to enhance the statistical significance of the results. In addition, detailed analyses looking at intermediate time points in the process of viral recovery would provide stronger conclusions about factors involved in the resistance induced by 'Garrigues' grafting. On the other hand, we must not forget that changes in the efficiency of RNA translation or in post-translational modifications of the protein, which would not be detected in RNA-seq experiments, could also contribute to the resistance induced in 'GF305' peach. Identifying these factors will require additional experimental approaches.

Our results show again that resistance to PPV in 'Garrigues' can be transmitted through the graft union through phloem and protect the highly susceptible 'GF305' peach. After a transcriptome analysis of seven samples (5 peaches and 2 almonds) by RNAseq (mRNA), we 
cannot determine the specific mechanisms of resistance that are regulating this surprising behaviour, so the next step is to clarify what is happening. If we are ultimately able to corroborate the "Garrigues effect" at the commercial level (nurseries and orchards), we will have an effective strategy against the continuous threat of PPV for peach production. Several candidate genes (including Glucan endo - 1,3-Beta DGlucosidase, Leucine rich repeat N-terminal domain, and Speckle-type POZ protein) up-regulated after almond grafting should be considered "susceptible" genes necessary for PPV infection. This down-regulation of the susceptible gene candidates should be due to a gene methylation process mediated by an sRNA molecule. On the other hand, transcriptomic results showed several defence genes, including RTM genes, NAM proteins, TFIIB, TLPs (Thaumatin like protein), and Dehydration-Responsive Proteins, over-expressed after 'Garrigues' grafting and therefore "resistance" genes to be responsible of this induced response. We propose that grafting provides a path for horizontal gene transfer. Based on these results, we can deduce the following resistant hypothesis of grafting 'Garrigues' to peach. First, grafting induced a series of signal transduction genes in high expression and there is an interesting correlation among constitutive thaumatin like protein, PR proteins, ABA compound, and disease susceptibility to PPV; secondly, protein kinase interacts with transcription factors or other factors and up-regulate the expression relevant susceptible genes.

\section{Methods}

\section{Biological material.}

Seedlings of peach 'GF305' peach are characterised by their susceptibility to fruit viruses including PPV ${ }^{48}$ and are used as a rootstock in PPV resistance tests on Prunus species under greenhouse conditions ${ }^{49}$. This material was used as rootstock for our grafting experiments with the 'Garrigues' almond cultivar. Firstly, 'GF305' peach seedlings, healthy or PPV-inoculated and showing sharka symptoms, were analysed. Later we proceeded to the analysis of almond-grafted peach plants (inoculated with PPV and control) to study the phenomenon of induced resistance. In these grafted plants, in order to identify the mechanism of systemic defence against PPV and the effector molecule that is intervening, a differential expression analysis was conducted by high-throughput sequencing mRNA (mRNA-Seq). The mRNA-Seq data was validated by RTqPCR in different 'GF305' and 'Garrigues' plants. The PPV isolate used was 3.30RB/GF-IVIA (GenBank: KJ849228.1), a Dideron Type (PPV-D) isolate obtained from the 'Red Beaut' Japanese plum variety in Spain in the 1980s and maintained in the PPV collection of the Instituto Valenciano de Investigaciones Agrarias (IVIA) in Valencia (Spain). This isolate produces strong sharka symptoms in young leaves of 'GF305' peach, consisting of venial chlorosis and rings.

\section{Sharka phenotyping and PPV detection.}

All the experiments were carried out in a greenhouse under controlled conditions. The complete evaluation procedure was described in Rubio et al. ${ }^{12}$. Briefly, plants were subjected to growth cycles in the greenhouse and rest periods in a cold chamber. Rootstocks were grown, inoculated with PPV and grafted with 'Garrigues' almond cultivars. During each evaluation cycle, plants were inspected for sharka symptoms, and PPV was detected by ELISA-DASI and RT-PCR tests. In the present work, three cycles of phenotyping were performed (Table 1). Sharka symptoms on leaves were scored using a scale from 0 (no symptoms) to 5 (maximum intensity), taking into account intensity and distribution in the plant as follows: 0 , no symptoms; 1 , discrete chlorosis or spots restricted to one or two leaves; 2 , slight chlorosis bordering leaf veins in three or more leaves; 3 , vein chlorosis or rings in numerous leaves; 4 , chlorosis, rings and some distortions on most leaves; and 5, strong chlorosis or distortions on all the leaves. The presence of PPV was confirmed by DASI-ELISA with the specific monoclonal antibody to the capsid protein (CP) of PPV 5B-IVIA/AMR (Plant Print Diagnostics SL, Valencia, Spain). Optical densities (OD) were recorded at $405 \mathrm{~nm}$ after 60 min of substrate incubation, and samples with OD double that of the healthy control were considered positive. Finally, for the detection of PPV RNA, total RNA was extracted from the same leaves subjected to the DASI-ELISA test using the RNeasy Plant Mini Kit® (Qiagen, Hilden, Germany), and RT-PCR analysis was carried out using specific primers for the coat protein coding sequence VP337 (5' CTCTGTGTCCTCTTCTTGTG 3') and VP338 (5' CAATAAAGCCATTGTTGGATC 3'). The enzymes used were Avian myeloblastosis virus reverse transcriptase and GoTaq ${ }^{\circledR} F$ lexi2 polymerase (Promega, Madison, WI). The RT-PCR parameters were $42^{\circ} \mathrm{C}$ for $45 \mathrm{~min}$ (cDNA synthesis) followed by one step at $94^{\circ} \mathrm{C}$ for $2 \mathrm{~min}$, and 35 cycles at $94^{\circ} \mathrm{C}$ for $30 \mathrm{~s}, 55^{\circ} \mathrm{C}$ for $30 \mathrm{~s}$ and $72{ }^{\circ} \mathrm{C}$ for $30 \mathrm{~s}$, with a final extension step at $72{ }^{\circ} \mathrm{C}$ for $5 \mathrm{~min}$. RT-PCR amplified products were separated by electrophoresis on $1 \%$ agarose gels in $40 \mathrm{mM}$ Trisacetate and 1 mM EDTA, pH 8.0, and stained with GelRed® (Biotium, USA) ${ }^{49}$.

\section{Experimental design and high-throughput mRNA sequencing.}

We assayed the following treatments: control (sample A) and PPV-infected 'GF305' peach seedlings showing strong sharka symptoms (sample B); control 'GF305' grafted with 'Garrigues' almond (samples C and F) and PPV-infected 'GF305' grafted with 'Garrigues' (samples D and G); and control 'GF305' grafted with 'Garrigues' almond and later inoculated with PPV (sample E) (Fig. 1). Leaf samples (a pool of leaves from five plants per replicate) from the evaluation cycle 2 (Table 1) were frozen in liquid nitrogen and stored at $-80^{\circ} \mathrm{C}$. Total RNA was extracted using the RNeasy Plant Mini Kit ${ }^{\circledR}$ (Qiagen, Hilden, Germany). The quality and quantity of the total RNA samples were assessed

Page $10 / 20$ 
using a NanoDrop ${ }^{\circledR} 2000$ spectrophotometer (Thermo Fisher Scientific, Wilmington, USA) and normalised at the same concentration $(200 \mathrm{ng} / \mu \mathrm{l})$. RNA samples $(5 \mu \mathrm{g})$ were sent to the Centre for Genomic Regulation (CRG, Barcelona, Spain) for library preparation and RNA sequencing. The 14 cDNA libraries of poly-A RNA were sequenced using an Illumina HiSeq2000 machine to perform 125 bp paired-end sequencing.

\section{Bioinformatic analysis.}

A quality control was performed for the RNA-Seq (mRNA) reads using PRINSEQ software ${ }^{50}$. In the mRNA analysis, adaptors were trimmed and low-quality bases at the ends of sequences and reads with undetermined bases or with $80 \%$ of their bases with less than $20 \%$ quality score were removed. High quality mRNA reads were mapped to the reference genome Prunus persica genome v2.0

(http://www.rosaceae.org/peach/genome) ${ }^{51}$ using STAR ${ }^{52}$. Genomic annotations were obtained from the Genome Database for Rosaceae (http://www.rosaceae.org/) in general feature format 3 (GFF3). The presence of the PPV virus was quantified by aligning the sequences that did not map to the peach genome against the PPV 3.30RB/GF-IVIA genome sequence (KJ849228.1) (Table 2). The transcript isoform (mRNA) level and gene level counts were calculated and FPKM (fragments per kilobase pair of transcript per million mapped reads) normalised using Cufflinks 2.2.1 software ${ }^{53}$. Total genes as well as tested genes were identified. Some of the total genes identified were not tested because of the very low number of reads detected. Differential transcript expression at the mRNA level was then computed using cuffmerge and cuffdiff ${ }^{54}$. After this, we selected those with a false discovery rate $(\mathrm{fdr})<0.05$ ( $\mathrm{p}$-value $\left.<0.05\right)$. The resulting lists of differentially expressed isoforms (mRNA) were then filtered by log2 (log fold change) $>1$ and $<-1$ and a q-value $<0.05$, taking into account all the identified genes in each comparison, including up- and down-regulated differentially expressed genes (Table 3, Supplementary TS9). The total list of unique DEG genes was used to perform a functional classification using PANTHER version $14^{55}$. In addition, an overrepresentation test was carried out using a GO-Slim annotation data set for each functional classification (molecular function, biological process and cellular component), and all genes were listed in the peach genome, according to Fisher's exact statistical test and Benjamini-Hochberg's False Discovery Rate correction. After that, results were plotted using an in-house python script using matplotlib ${ }^{56}$. In addition, Venn diagrams were generated using the online tool from the University of Ghent (http://bioinformatics.psb.ugent.be/webtools/Venn).

\section{RT-qPCR validation of selected transcripts.}

To validate the RNA-Seq analysis, RT-qPCR was performed in a new experiment with new plant materials assaying three biological replicates per treatment. Total RNA was extracted using the Rneasy Plant Mini Kit ${ }^{\circledR}$ and subjected to reverse transcription with the PrimeScript ${ }^{\circledR}$ Reverse Transcriptase Kit (Invitrogen, Applied Biosystems, Madrid, Spain). Relative quantitative PCR (qPCR) experiments were executed with StepOnePlus ${ }^{\text {TM }}$ real-time PCR system (Applied Biosystems). Specific primers were designed based on peach/almond sequences previously obtained using Primer3 software (Table S1). A total of 17 qPCR reactions were performed, including 13 differentially expressed new genes and three internal controls as previously described by Rubio et al. ${ }^{12}$. qPCR efficiency was checked by the standard curve method. For all real-time qPCR reactions, a $10 \mu \mathrm{lmix}$ was made containing: $5 \mu$ l Power SYBR ${ }^{\circ}$ Green PCR Master Mix (Applied Biosystems), 10 to $20 \mathrm{ng}$ of cDNA, and $2.5 \mu \mathrm{M}$ of each primer. The qPCR conditions were as follows: $95^{\circ} \mathrm{C}$ for $10 \mathrm{~min} ; 40 \mathrm{cycles}$ of $95^{\circ} \mathrm{C}$ for $15 \mathrm{~s}$ and $60^{\circ} \mathrm{C}$ for $1 \mathrm{~min}$. The melting temperature in these experiments was set to $60^{\circ} \mathrm{C} \sim 95^{\circ} \mathrm{C}$ and increasing by $0.3^{\circ} \mathrm{C} / \mathrm{s}$. Each biological sample was implemented in triplicate. RPII, actin and expansin-A8 were used as reference genes for data normalisation ${ }^{57}$, and the levels of relative expression were calculated by the comparative method ${ }^{58}$, taking $\mathrm{Ct}$ value from the first samples (treatment $\mathrm{A}$ ) as the reference expression level.

\section{Declarations}

\section{Conflict of Interest Statement}

The authors declare that the research was conducted in the absence of any commercial or financial relationships that could be construed as a potential conflict of interest.

\section{Author Contributions}

M.R., P.J.M.-G, A.N.-D., A.S.P., E.G. and P.M.-G contributed to laboratory experiments, bioinformatics and data analysis. M.R. performed the phenotypic evaluation. M.R., F.D., B.R., J.A.G. and P.M.-G. participated in the design and coordination of the study and the manuscript elaboration. All authors discussed the results and commented on the manuscript.

\section{Acknowledgments and Funding}


The authors want to acknowledge the technical assistance of Teresa Cremades. This study has been supported by the projects "Epigenetic regulation of the resistance to Plum pox virus (sharka) induced in peach by almond grafting and its application as interstock

(ALMOND4SHARKA)" of the Spanish Ministry of Science, Education and Universities (RTI2018-095556-B-I00). The work of B.R and J.A.G was supported by grant PID2019-109380RBI00 / AEI /301 10.13039/501100011033 from the Spanish Ministry of Science and Innovation.

\section{References}

1. Rubio, M. et al. Recent advances and prospects in Prunus virology. Ann. Appl. Biol. 171, 125-138 (2017).

2. Sihelská, N., Glasa, M. \& Šubr, Z. W. Host preference of the major strains of Plum pox virus -Opinions based on regional and worldwide sequence data. J. Integr. Agr. 16, 510-515 (2017).

3. Scholthof, K. B. G. et al. Top 10 plant viruses in molecular plant pathology. Mol. Plant Patol. 12, 938-954 (2011).

4. García, J. A., Glasa, M., Cambra, C. \& Candresse, T. Plum pox virus and sharka: A model potyvirus and a major disease. Mol. Plant Pathol. 15, 226-241 (2014).

5. Sochor, J., Babula, P., Adam, V., Krska, B. \& Kizek, R. Sharka: The past, the present and the future. Viruses 4, 2853-2901(2012).

6. Martínez-Gómez, P., Dicenta, F. \& Audergon, J. M. Behaviour of apricot (Prunus armeniaca L.) cultivars in presence of sharka (Plum pox virus): a review. Agronomie. 20, 407-422 (2000).

7. Rubio, M., Martínez-Gómez, P. \& Dicenta, F. Resistance of almond cultivars to Plum pox virus (sharka). Plant Breed. 122, 462-464 (2003).

8. Rubio, M., Martínez-Gómez, P., Pascal, T. \& Dicenta, F. Sensitivity of peach cultivars against a Dideron isolate of Plum pox virus. Sci. Hort. 144, 81-86 (2012).

9. Cirilli, M. et al. Fighting sharka in peach: Current limitations and future perspectives. Front. Plant Sci. 7, 1290 (2016).

10. Rubio, M., Pascal, T., Bachellez, A. \& Lambert, P. Quantitative trait loci analysis of PPV resistance in Prunus davidiana P1908. Tree Genet. Gen. 6, 291-304 (2010).

11. Martínez-Gómez, P., Rubio, M., Dicenta, F. \& Gradziel, T. M. Resistance to Plum pox virus (RB3.30 isolate) in a group of California almonds and transfer of resistance to peach. J. Amer. Soc. Hort. Sci. 129, 544-548 (2004).

12. Rubio, M., Martínez-Gómez, P., García, J. A. \& Dicenta, F. Interspecific transfer of resistance to Plum pox virus from almond to peach by grafting. Ann. Appl. Biol. 163, 466-474 (2013).

13. Rubio, M. et al. Analysis of gene expression changes in peach leaf tissues in response to Plum pox virus infection using RNA-SEq. Mol. Plant Pathol. 16, 164-176 (2015).

14. Nikbakht-Dehkordi, A., Rubio, M., Babaeian, N., Albacete, A. \& Martínez-Gómez, P. Phytohormone Signaling of the Resistance to Plum pox virus (PPV, Sharka Disease) Induced by Almond (Prunus dulcis (Miller) Webb) Grafting to Peach (P. persica L. Batsch). Viruses. 10, 238 (2018).

15. Ratcliff, F., Harrison, B. D. \& Baulcombe, D. C. A similarity between viral defense and gene silencing in plants. Science. 276, 1558-1560 (1997).

16. Guo, H. S. \& Garcia, J. A. Delayed resistance to plum pox potyvirus mediated by a mutated RNA helicase gene: Involvement of a gene silencing mechanism. Mol. Plant-Microbe Interact. 10, 160-170 (1997).

17. Pallás, V. \& García, J. A. How do plant viruses induce disease? Interactions and interference with host componenents. J. General Virol. 92, 2691-2705 (2011).

18. Stegemann, S. \& Bock, R. Exchange of genetic material between cells in plant tissue grafts. Science. 314, 649-651 (2009).

19. Harada, J. Grafting and RNA transport via phloem tissue in horticultural plants. Scientia Hort. 125, 545-550 (2010).

20. Haroldsen, V. M., Szczerba, M. W., Aktas, H., Lopez-Baltazar, J. \& Odias, M. J. Mobility of Transgenic Nucleic Acids and Proteins within Grafted Rootstocks for Agricultural Improvement. Front. Plant Sci. 3, 39 (2012).

21. Chen, W. W. et al. A mobile ELF4 delivers circadian temperature information from shoots to roots. Nature Plants. 6, 416-426 (2020).

22. Molnar, A., Melnyk, C. W., Bassett, A., Hardcastle, T. J. \& Dunn, R. Small silencing RNAs in plants are mobile and direct epigenetic modification in recipient cells. Science. 328, 872-875 (2010).

23. Lewsey, M. G. et al. Mobile small RNAs regulate genome-wide DNA methylation. Proc. Natl. Acad. Sci. U.S.A. 113, E801-E810(2016).

24. Pagliarani, C., Gambino, G., Small, R. N. A. \& Mobility Spread of RNA Silencing Effectors and its Effect on Developmental Processes and Stress Adaptation in Plants. Int. J. Mol. Sci. 20, 4306 (2019).

Page $12 / 20$ 
25. Dandekar, A. M. et al. Trans-Graft Protection Against Pierce's Disease Mediated by Transgenic Grapevine Rootstocks. Frontiers Plant Sci. 10, 84 (2019).

26. Spanò, R. et al. Grafting alters tomato transcriptome and enhances tolerance to an airborne virus infection. Sci. Rep. 10, 2538 (2020).

27. Webster, A. D. Rootstock and interstock effects on deciduous fruit tree vigour, precocity, and yield productivity. New Zealand J. Crop Hort. Sci. 23, 373-382 (1995).

28. Rubio, M. et al. Gene expression analysis of Plum pox virus (Sharka) Susceptibility/Resistance in apricot (Prunus armeniaca L.). PLOS One. 10, e0144670 (2015).

29. Yu, B. et al. Methylation as a Crucial Step in Plant microRNA Biogenesis. Science. 307, 932-935 (2005).

30. Collum, T. D. et al. Translatome profiling of Plum pox virus infected leaves in European plum reveals temporal and spatial coordination of defense responses in phloem tissues. Mol. Plant-Microbe Interact. 33, 66-77 (2020).

31. Beffa, R. S., Hofer, R. M., Thomas, M. \& Meins, F. Decreased susceptibility to virus disease of $\beta$-1,3-glucanase-deficient plants generated by antisense transformation. Plant Cell. 8, 1001-1011 (1996).

32. Díaz-Vivancos, P. et al. The apoplastic antioxidant system in Prunus: response to long-term Plum pox virus infection. J. Exp. Bot. 57, 3813-3824 (2006).

33. Lefevere, H., Bauters, L. \& Gheysen, G. Salicylic Acid Biosynthesis in Plants. Frontiers in Plant Science. 11, 338 (2020).

34. Lu, H. P. et al. Resistance of rice to insect pests mediated by suppression of serotonin biosynthesis. Nature Plants. 4, 338-344 (2018).

35. Pasin, F. et al. Abscisic acid connects phytohormone signaling with RNA metabolic pathways and promotes an antiviral response that is evaded by a self-controlled RNA Virus. Plant Communications. 1, 100099 (2020).

36. Abe, H. et al. Arabidopsis AtMYC2 (bHLH) and AtMYB2 (MYB) function as transcriptional activators in Abscisic Acid signaling. The Plant Cell. 15, 63-78 (2003).

37. Alazem, M. \& Lin, N. S. Roles of plant hormones in the regulation of host-virus interactions. Mol. Plant Pathol. 16, 529-540 (2015).

38. Puranik, S., Sahu, P. P., Srivastava, P. S. \& Prasad, M. NAC proteins: regulation and role in stress tolerance. Trends Plant Sci. 17, 369381 (2012).

39. Ren, T., Qu, F. \& Morris, J. H. R. T. Gene Function Requires Interaction between a NAC Protein and Viral Capsid Protein to Confer Resistance to Turnip Crinkle Virus. Plant Cell. 12, 1917-1925 (2000).

40. Espinoza, C., Vega, A., Schlauch, K. \& Arce-Jhonson, P. Gene expression associated with compatible viral diseases in grapevine cultivars. Funct. Integr. Gen. 7, 95-110 (2007).

41. Cabot, C., Martos, S., Llugany, M., Gallego, B. \& Tolrà, R. Poschenrieder, C. A Role for Zinc in plant defense against pathogens and herbivores. Frontiers in Plant Science. 10, 1171 (2019).

42. Mani, R. S. The emerging role of speckle-type POZ protein (SPOP) in cancer development. Drug Discov Today. 19, 1498-1502 (2014).

43. Decroocq, V. et al. The determinant of potyvirus ability to overcome the RTM resistance of Arabidopsis thaliana maps to the N-terminal region of the coat protein. Mol. Plant-Microbe Intear. 22, 1302-1311 (2009).

44. Pagny, G. et al. Family-based linkage and association mapping reveals novel genes affecting Plum pox virus infection in Arabidopsis thaliana. New Phytol. 196, 873-886 (2012).

45. Zuriaga, E. et al. Genomic analysis reveals MATH gene(s) as candidate for Plum pox virus (PPV) resistance in apricot (Prunus armeniaca L.). Mol. Plant Pathol. 13, 663-677 (2013).

46. Zuriaga, E., Romero, C., Blanca, J. M. \& Badenes, M. L. Resistance to Plum pox virus (PPV) in apricot (Prunus armeniaca L.) is associated with down-regulation of two MATHd genes. BMC Plant Biol. 18, 25 (2018).

47. Polo-Oltra, Ã., Romero, C., López, I., Badenes, M. L. \& Zuriaga, E. Cost-Effective and Time-Efficient Molecular Assisted Selection for Ppv Resistance in Apricot Based on ParPMC2 Allele-Specific PCR. Agronomy. 10, 1292 (2020).

48. Bernhard, R., Marénaud, C. \& Sutic, D. Le pêcher GF305 indicateur polyvalent des virus des espèces à noyaux. Ann. Phytopathol. 1, 603-617 (1969).

49. Rubio, M., García-Ibarra, A., Martínez-Gómez, P. \& Dicenta, F. Analysis of the main factors involved in the evaluation of Prunus resistance to Plum pox virus (Sharka) in control greenhouse conditions. Sci. Hort. 123, 46-50 (2009).

50. Schmieder, R. \& Edwards, R. Quality control and preprocessing of metagenomic datasets. Bioinformatics. 27, 863-864 (2011).

51. Verde, I. et al. The Peach v2.0 release: high-resolution linkage mapping and deep resequencing improve chromosome-scale assembly and contiguity. BMC Gen. 18, 225 (2017).

52. Dobin, A. et al. STAR: ultrafast universal RNA-seq aligner. Bioinformatics. 29, 15-21 (2013).

Page $13 / 20$ 
53. Trapnell, C. et al. Differential analysis of gene regulation at transcript resolution with RNA-SEq. Nature Biotech. 31, 46-53 (2013).

54. Li, B. et al. RNA-Seq methods for identifying diffrentially expressed gene in human pancreatic islet treated with pro-inflamatory cytokines. Mol. Biol. Report. 41, 1917-1925 (2014).

55. Mi, H., Muruganujan, A., Ebert, D., Huang, X. \& Thomas, P. D. PANTHER version 14: more genomes, a newPANTHER GO-slim and improvements in enrichmentanalysis tools. Nucleic Acids Res. 47, D419-D426 (2009).

56. Hunter, J. D. \& Matplotlib A 2D Graphics Environment. Computing Sci. Engi. 9, 90-95 (2007).

57. Tong, Z., Gao, Z., Wang, F., Zhou, J. \& Zang, Z. Selection of reliable reference genes for gene expression studies in peach using real-time PCR. BMC Mol. Biol. 10, 71 (2009).

58. Pfaffl, M. W. A new mathematical model for relative quantification in real-time RT-PCR. Nucl. Acids Res. 29, e45 (2001).

\section{Supplementary Materials}

The Supplementary Material for this article can be found online.

Table S1. Primer sequences representing a set of sixteen differentially expressed genes in the different treatments and three internal controls selected for qPCR.

Table S2. Total genes identified, total genes tested; total ( $p$-val<0.05) and filtered ( $q$-val<0.05) differentially expressed (DE) genes in the B/A comparison (GF305 + PPVvs.GF305 Control). In bold type: the evaluated plant material, GF305 = peach.

Table S3. Total genes identified, total genes tested; total ( $p$-val<0.05) and filtered ( $q-v a l<0.05)$ differentially expressed (DE) genes in the C/A comparison (GF305 Control + Garrigues vs GF305 Control). In bold type: the evaluated plant material, GF305 = peach and Garrigues = almond.

Table S4. Total genes identified, total genes tested; total ( $p$-val<0.05) and filtered (q-val<0.05) differentially expressed (DE) genes in the $D / B$

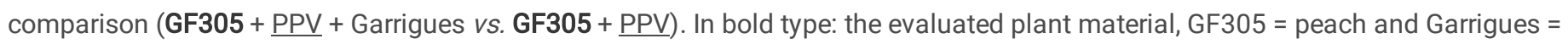
almond.

Table S5. Total genes identified, total genes tested; total ( $p$-val<0.05) and filtered (q-val<0.05) differentially expressed (DE) genes in the D/C

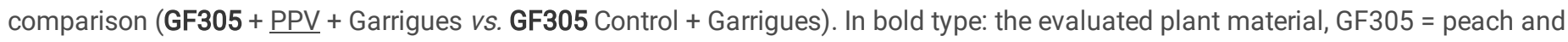
Garrigues = almond.

Table S6. Total genes identified, total genes tested; total ( $p$-val<0.05) and filtered (q-val<0.05) differentially expressed (DE) genes in the E/B comparison (GF305 Control + Garrigues $+\underline{\text { PPV } v s . ~ G F 305 ~}+\underline{\text { PPV }}$ ). In bold type: the evaluated plant material, GF305 = peach and Garrigues = almond.

Table S7. Total genes identified, total genes tested; total ( $p$-val<0.05) and filtered ( $q-\mathrm{val}<0.05)$ differentially expressed (DE) genes in the E/D comparison (GF305 + PPV + Garrigues vs. GF305 Control + Garrigues + PPV). In bold type: the evaluated plant material, GF305 = peach and Garrigues = almond.

Table S8. Total genes identified, total genes tested; total ( $p$-val<0.05) and filtered ( $q$-val<0.05) differentially expressed (DE) genes in the G/F comparison (GF305 + PPV + Garriguesvs. GF305 Control + Garrigues). In bold type: the evaluated plant material, GF305 = peach and Garrigues = almond.

Table S9. Total filtered DEG comparisons with up- and down-regulated genes, including comparisons B/A; C/A; D/B; E/B; D/C and E/D. Additionally, we have included five genes that do not pass the DEG filter.

Table S10. Total list of unique DEG genes (3210), including all comparisons, used to perform an overrepresentation test by Fisher's exact statistical test and Benjamini-Hochberg's False Discovery Rate.

Table S11. Total list of unique filtered DEG genes (147) including all comparisons, used to perform an overrepresentation test by Fisher's exact statistical test and Benjamini-Hochberg's False Discovery Rate.

Table S12. Total list of unique filtered DEG genes (82) including comparisons CA vs. DB vs. EB used to perform an overrepresentation test by Fisher's exact statistical test and Benjamini-Hochberg's False Discovery Rate. 
Table S13. Total list of unique filtered DEG genes (113) including comparisons BA vs. DB vs. EB vs. DC used to perform an overrepresentation test by Fisher's exact statistical test and Benjamini-Hochberg's False Discovery Rate.

\section{Figures}

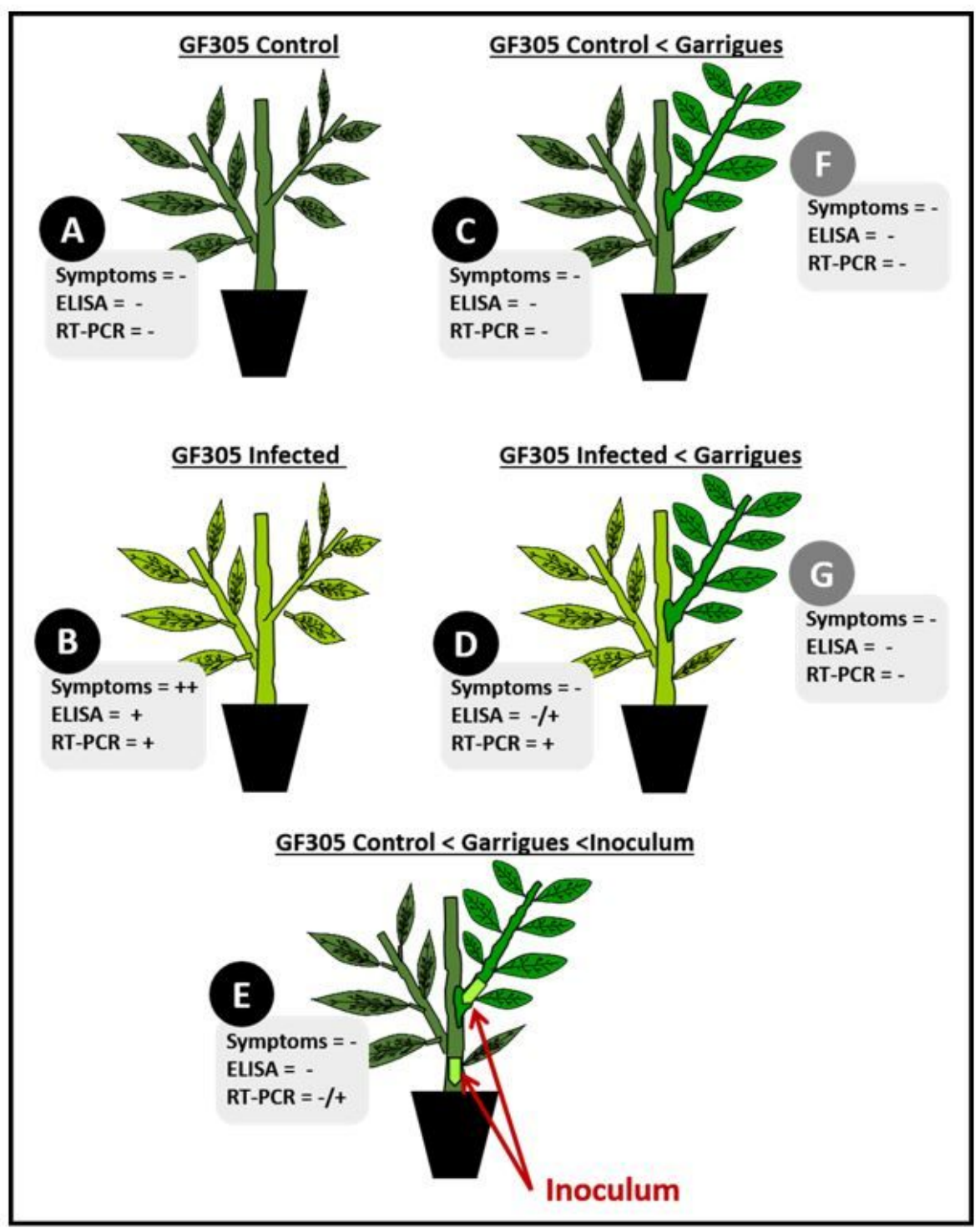

Figure 1

Schematic representation of the assayed treatments including symptoms, ELISA and RT-PCR: (A) control healthy 'GF305' peach rootstocks; (B) PPV-infected 'GF305' rootstocks showing very severe sharka symptoms; (C) healthy 'GF305' peach rootstocks grafted with 'Garrigues'; (D) PPV-infected 'GF305' rootstocks showing sharka symptoms grafted with 'Garrigues'; and (E) healthy 'GF305' peach rootstocks grafted with 'Garrigues' which were later inoculated with PPV at the end of the first cycle of evaluation. In addition, 'Garrigues' almond samples grafted onto healthy (F) and PPV-inoculated 'GF305' (G) rootstocks were included in the study. 

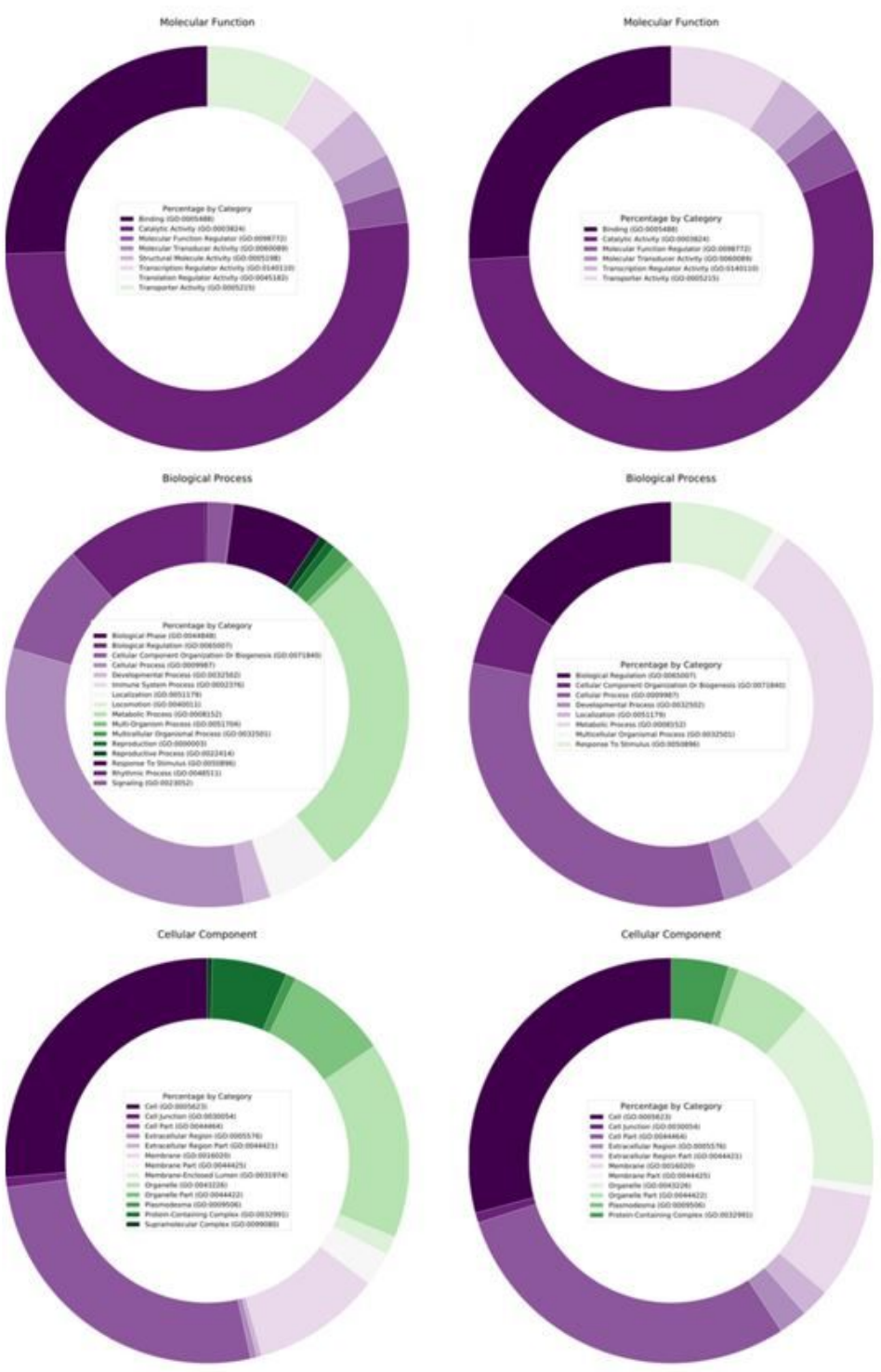

\section{Figure 2}

GO term categories obtained by PANTHER. Functional analysis of differentially expressed genes including all comparisons (3210; left side) and functional analysis of filtered differentially expressed genes (147; right side). Diagrams show percentage of GO term categories showing the total of each domain for Cellular Components, Biological processes and Molecular Functions domains. 
A

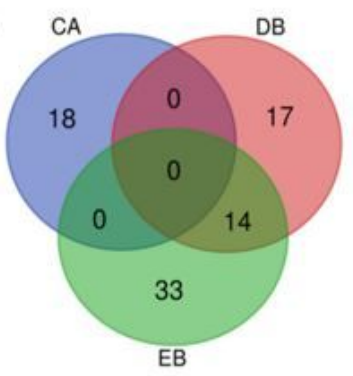

B
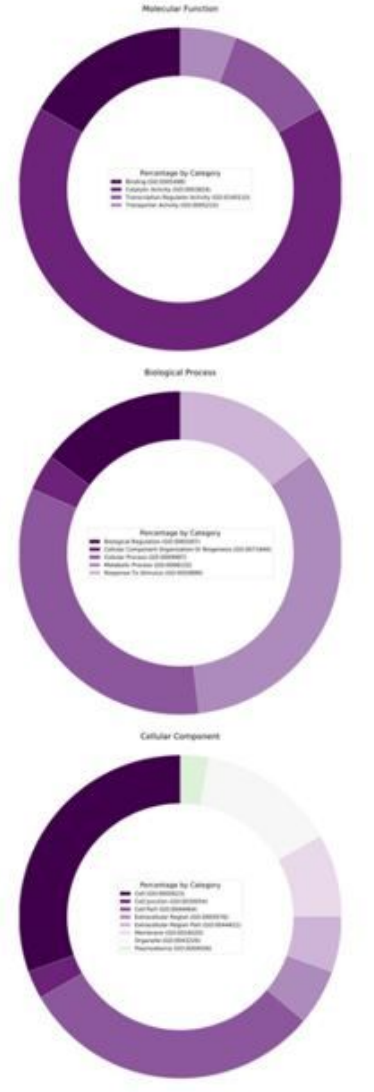
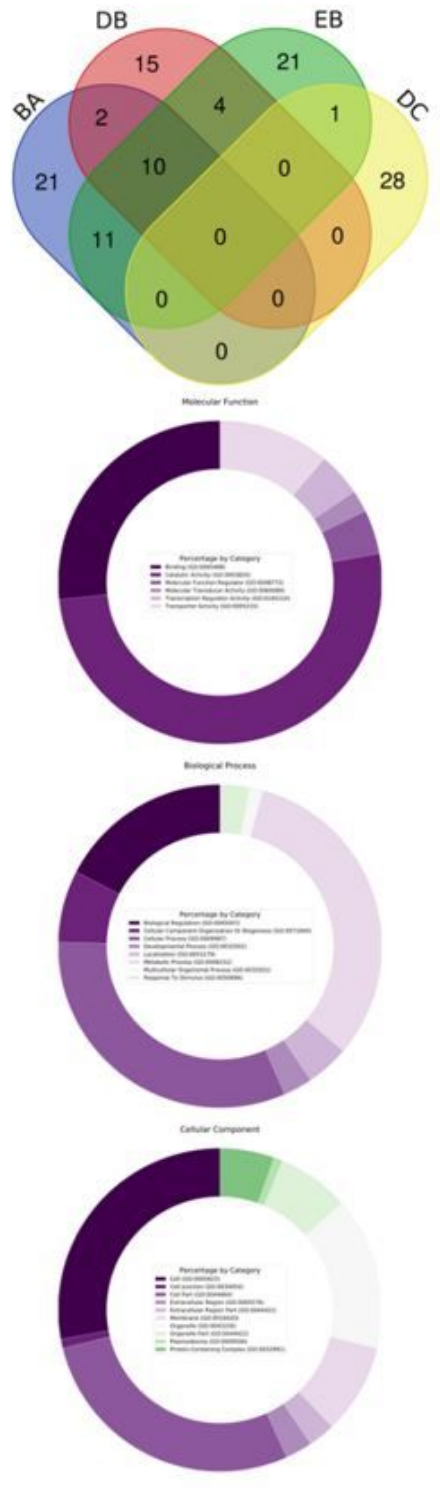

\section{Figure 3}

A) Analysis of DEGs associated with grafting (CA vs. DB vs. EB) (left) and inoculation (BA vs. DB vs. EB vs. DC) (right) effects. B) GO term categories obtained by PANTHER for DEGs associated with grafting (left) and inoculation (right) effects. Diagram shows percentage of GO term categories showing the total of each domain for DEGs Cellular Components, Biological processes and Molecular Functions domains. 
Gibberellin-regulated protein 4

(0.95)

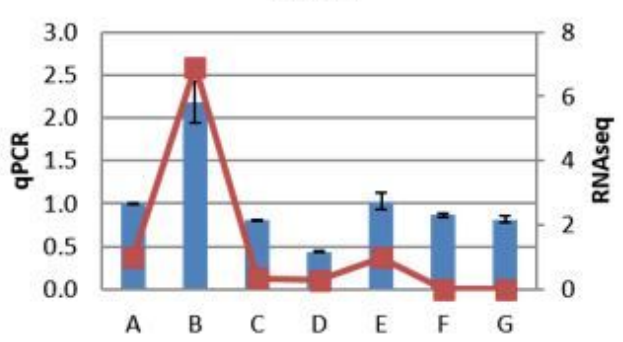

Ethylene-responsive TF ERF017

(0.79)

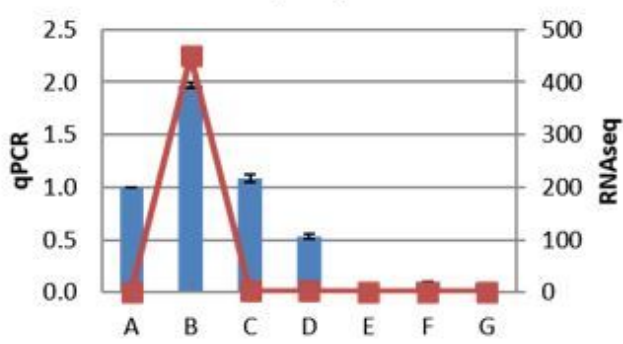

Chorismate mutase

(0.75)

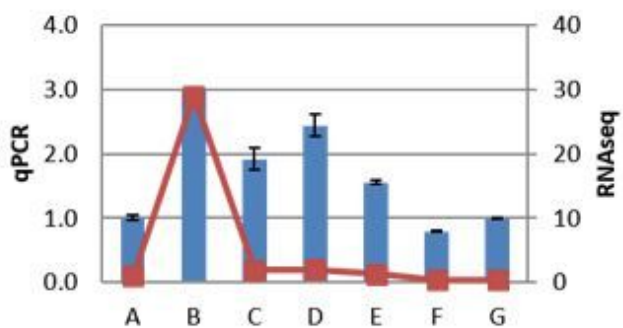

Dehydration-responsive protein RD22

(0.91)

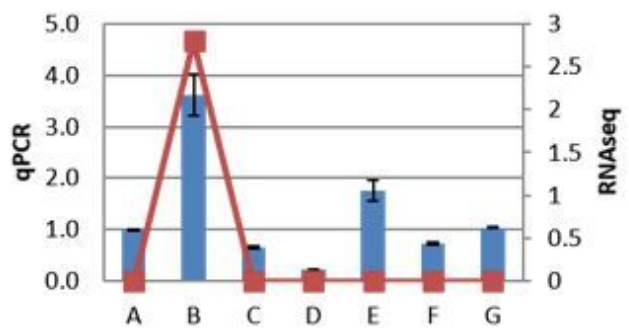

EREBP-like factor

(0.84)

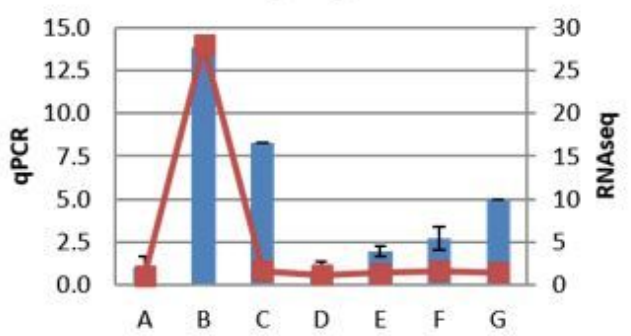

Cytochrome P450 71A1

(0.81)

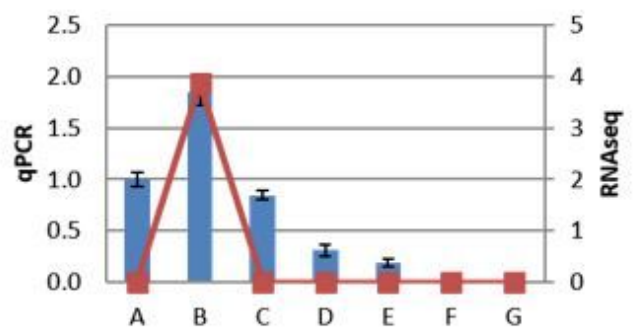

Figure 4

RT-qPCR expression analysis (blue bars) for candidate genes involved in phytohormonal signalling, including a phytohormone related to growth like the gibberellin (GA) (Prupe.5G193400; Gibberellin-regulated protein 4); phytohormones related to stress like abscisic acid (ABA) (Prupe.1G453700; Dehydration-responsive protein RD22); ethylene (Prupe.7G194400; Ethylene-responsive transcription factor ERF017 and Prupe.4G176200; Ethylene responsive element binding protein (ERBP)-like factor); and salicylic acid (SA) (Prupe.1G393400; Chrorismate mutase; (Prupe.5G164200; Cytochrome P450 71A1 (CYP71A1), all selected from the RNA-Seq analysis. Relative gene expression (RGE) in the seven samples: control healthy 'GF305' peach rootstocks (A); PPV-infected 'GF305' rootstocks showing very severe sharka symptoms (B); 'GF305' peach rootstocks grafted with healthy 'Garrigues' (C); PPV-infected 'GF305' rootstocks showing sharka symptoms grafted with healthy 'Garrigues' (D); and healthy 'GF305' peach rootstock grafted with healthy 'Garrigues' which were later inoculated with PPV at the end of the first cycle of evaluation (E). 'Garrigues' almond samples grafted onto healthy (F) and inoculated 'GF305' (G) rootstocks. Error bars in qPCR represent the standard error of three independent biological replicates. Between brackets: Pearson correlation coefficients between FPKM (fragments per kilobase pair of transcript per million mapped reads) values from RNA-Seq (in red lines) and RGE values from qPCR. 

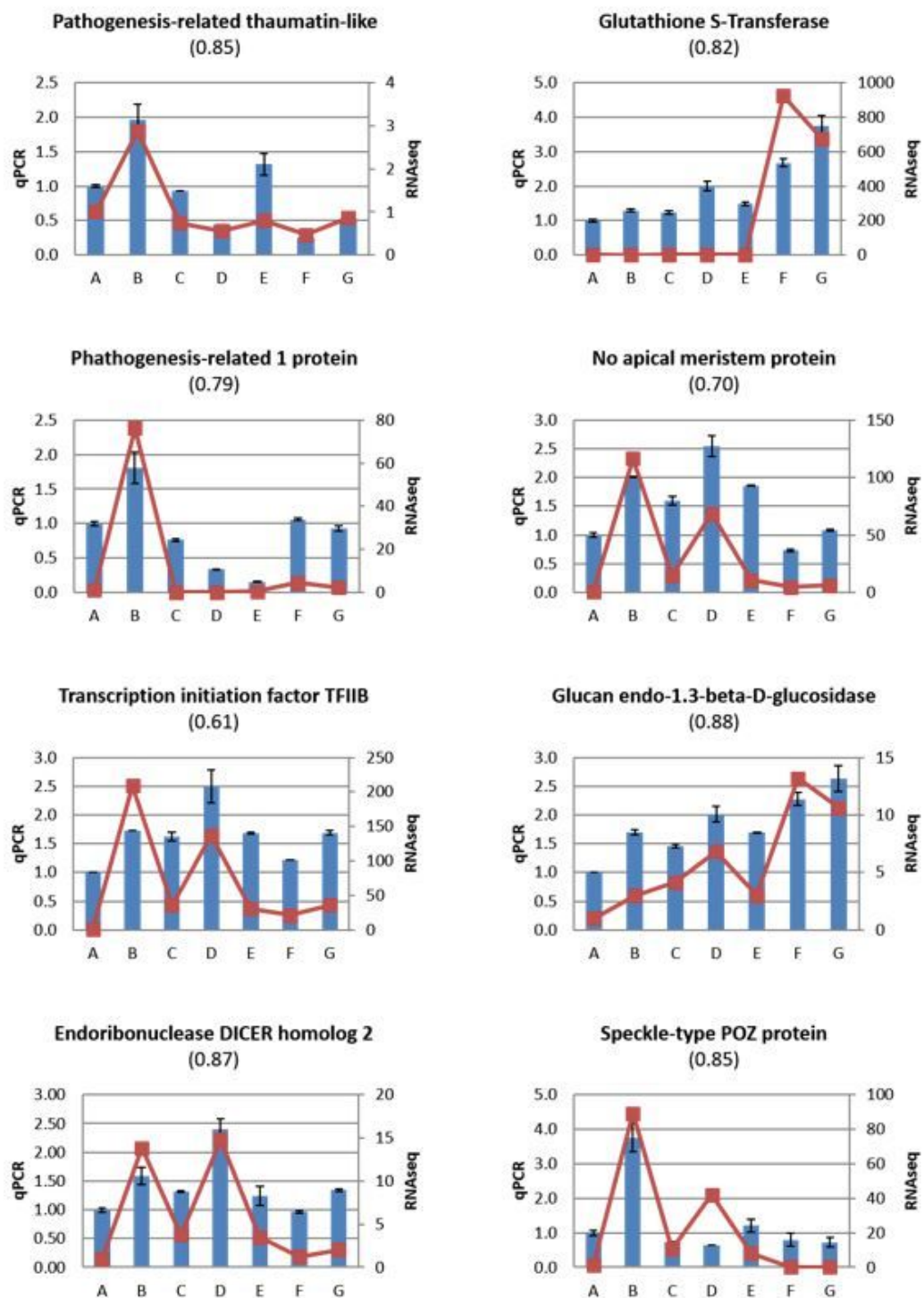

\section{Figure 5}

RTqPCR expression analysis for candidate genes related to the pathogen response selected from the RNA-Seq analysis (blue bars) including: Pathogenesis-related thaumatin-like protein (Prupe.8G163300), Glutathione S-Transferase (Prupe.1G039900), Pathogenesisrelated 1 protein (Prupe.1G091400), No apical meristem protein (Prupe.2G204700), Transcription initiation factor TFIIB (Prupe.3G255800), Glucan endo-1,3-beta-D-glucosidase (Prupe.7G051200), Endoribonuclease DICER homolog 2 (DCL2) (Prupe.7G048000) and Speckle-type POZ protein (Prupe.1G488200) Relative gene expression (RGE) in the seven samples: control healthy 'GF305' peach rootstocks (A); PPVinfected 'GF305' rootstocks showing very severe sharka symptoms (B); 'GF305' peach rootstocks grafted with healthy 'Garrigues' (C); PPVinfected 'GF305' rootstocks showing sharka symptoms grafted with healthy 'Garrigues' (D); and healthy 'GF305' peach rootstock grafted with healthy 'Garrigues' which were later inoculated with PPV at the end of the first cycle of evaluation (E). 'Garrigues' almond samples grafted onto healthy $(F)$ and inoculated 'GF305' (G) rootstocks. Error bars in qPCR data represent the standard error of three independent biological replicates. Between brackets: Pearson correlation coefficients between FPKM (fragments per kilobase pair of transcript per million mapped reads) values from RNA-Seq (in red lines) and RGE values from qPCR.

\section{Supplementary Files}

This is a list of supplementary files associated with this preprint. Click to download.

- Rubioetal.TableS1Revised.xlsx

- Rubioetal.TableS10Revised.xlsx 
- Rubioetal.TableS11Revised.xlsx

- Rubioetal.TableS12Revised.xlsx

- Rubioetal.TableS13Revised.xlsx

- Rubioetal.TableS2Revised.xIsx

- Rubioetal.TableS3Revised.xIsx

- Rubioetal.TableS4Revised.xlsx

- Rubioetal.TableS5Revised.xlsx

- Rubioetal.TableS6Revised.xIsx

- Rubioetal.TableS7Revised.xlsx

- Rubioetal.TableS8Revised.xlsx

- Rubioetal.TableS9Revised.xlsx 